Board on "The Distribution and Seasonal Abundance of the Flat-fishes in the North Sea," by Dr. Fulton. This is also largely a statistical paper, and somewhat overlaps Henking's work in the North Sea and the Cattegat, and Dr. Heincke's, so far as flat-fishes are concerned. A main point is the "complementary and compensatory fluctuations" in the statistics, e.g. the "witch" or pole-dab in square xiv., near the Fair Isle, taking, during the winter, the place of dabs, lemon dabs, and plaice. Uncertainty, however, exists, as no other method of fishing than trawling was used on the same ground to make sure the other forms were not there. This condition is well known to fishermen. In regard to the maximum of the captures in each fish, it is found that it corresponds to the spawning season. While this paper likewise does not deal directly with the great question handed over to the Scotch Board to solve, it indirectly supports the "Resources of the Sea" in so far as the total average of lbs. per hour of fishing was greater (in flat-fishes) in 1903 than in rgor.

One of the most important papers is that of Dr. H. M. Kyle, who shows that the quantity of fish of all kinds landed in the North Sea ports, and especially of flat-fishes, was greater in 1903 than in 1902. This is clearly substantiated by Johansen's observations on Danish plaice. Hjort's work, again, removes any fear of diminution of round fishes for the supply of the North Sea.

While, therefore, the work of the British international observers up to date does not show an answer to the fundamental question submitted by the Government, yet it inadvertently supports the "Resources of the Sea," and is fairly compatible with the safety of the fishes in the North Sea. Finally, a separate English Fisheries Board, as Lord Dalhousie recommended, was suggested.

\section{NEW ZEALAND PETROGRAPHY.'}

THE first volume of this work was reviewed in NATURE of January 4, 1906, vol. 1xxili., gp. 234, 235. We noticed in that place the reasons which led to these Cape Colville rocks being selecyed for spelatudy, and also the circumstances putich necessary to call in extraneous fid for he acscriptive part of the work. Of the volume $\mathrm{n}$ w we use the first two-thirds, to which alone the ple of the book is properly applicable, completes the account of the volcanic rocks of the Cape Colville Peninsula. As before, the petrographical descriptions are by Prof. Sollas, and the notes relative to locality and occurrence by $\mathrm{Mr}$. McKay, who also furnishes a clear geological map of the district. The details of mineralogical composition and micro-structure do not include much that is new, though we may mention the occurrence of a felspar of the anorthoclase type in some of the rhyolites, the frequent association of hornblende (or its pseudomiorphs) with hypersthene in the andesitic rocks, and the presence of olivine in certain basic hypersthene-andesites or hypersthene-basalts. The interest of this collection of Tertiary andesites, dacites, and rhyolites lies, not so much in any novelty which they present, as in the close resemblance of the whole assemblage from this " petrographical province" to familiar types from better-known areas, such as Hungary and the Great Basin of North America.

The lack of arrangement and some minor blemishes, on which we will not insist, are drawbacks doubtless incidental to the conditions under which the work was carried out, by the cooperation of a petrologist in England with a field-geologist at the Antipodes. When this investigation was taken in hand, Mr. McKay, we believe, embodied in his own person the Geological Survey of New Zealand, and the work must be considered a notable production in these adverse circumstances. The re-organised Geological Survey, under the directorship of Dr. J. M. Bell, has begun operations with greater advantages, and two important memoirs of the new series have already appeared.

A special feature of the present work is the profusion of plates. This was not, we understand, a part of the

1 "The Rocks of Cape Colvil'e Peninsula, Aucklant, New Zealand." By Prof. Sollas. F.R.C. . with an. Introduction and Desrriotive Notes by Alexonder McKay. Vol. ii. Pr. 215 : with geological man and $\mathrm{r}_{33}$ photographic plates of rcck-sections. (Wellingtnn, N.Z. : J. McKay, 19c6.) No. I969, voL. 76] original design, but it greatly enhances the value of the book. In the two volumes more than two hundred fullpage plates are devoted to the illustration of the volcanic rocks of the Cape Colville Peninsula alone. The thin slices have been photographed with polarised light, usually with an amplification of sixty diameters, and most of the plates are very successful in rendering the micro-structure of the rocks selected. Such a collection of illustrations is welcome independently of the immediate object of the boak, and the fact that most of the rocks belong to types of world-wide distribution is, from this point of view, an advantage.

The latter part of this volume is devoted to the description and illustration of various rocks from numerous places in New Zealand. Some of these, from the Kaimanawa Mountains and other localities in the North Island, are volcanic rocks generally comparable with those of Cape Colville. Other descriptions are included here, without regard to relationship, to fill out the volume, and the want of any orderly arrangement gives a somewhat confused appearance to this section. Some remarkable teschenites are described from the east coast of Wellington Province. They appear to occupy the neck of an old volcano, and it is noteworthy that, like the similar rocks from some European localities, they are referred to a Cretaceous age. Special interest attaches to a collection of crystalline schists from Westland Province, on the west side of the South Island. In addition to garnetiferous mica-schists, epidote-amphibole-schists, and other ordinary types, there occurs a series of schistose ultrabasic rocks composed of serpentine, talc, tremolite, calcite, \&c. Through the same district there runs also a belt of massive ultrabasic rocks, viz. fresh and altered dunites. The geological relations of these two very interesting groups are only briefly touched in this work, but they are fully discussed in the first Bulletin (new series) of the Geological Survey, already mentioned.

Prof. Sollas's investigations, while devoted mainly to the exhaustive description of one group of rocks, afford also a glimpse of the rich variety of material which New Zealand offers to the petrographer. When we recall further the widely different " petrographical province" of Dunedin, characterised by highly alkaline rock-types, some of which have recently been described by Dr. Marshall, we may expect that a more comprehensive examination of the igneous and crystalline rocks of the colony will result in further important additions to petrological science.

A. $\mathrm{H}$.

\section{UNSOLVED PRCBLEMS IN THE DESIGN AND PROPULSION OF SHIPS. ${ }^{1}$}

THERE are but few problems in the design of ships, as in most other branches of engineering, that can be exactly or completely solved in the full scientific meaning of the word, and those are of a secondary character. The primary or fundamental problems of safety, strength, speed, and steadiness at sea are far too complicated to bring under anything like general mathematical treatment. The results obtained by the most advanced calculations cannot be applied directly to the real conditions of a ship at sea. After all is said and done, they merely relate to hypothetical cases which are simple in character and are amenable to mathematical treatment. Some of these calculations are very elaborate, and their elaboration may sometimes tend to magnify their importance. The real problem is often very imperfectly dealt with after they are made, and it can only be solved approximately for working purposes by accepting the results of calculation for what they may be really worth, judging of the allowances required for their incompleteness, and using them in a scientific way and a scientific spirit to arrive at safe conclusions. We are obliged to come to a conclusion somehow, because we have to build ships as well as we can, whether we can solve exactly all the problems that arise in their design or not;:and we have to take the responsibility of guaranteeing results, however difficult to obtain, or of decliring to do so, within the time allotted for the preparation of

1 Abridged from the "James Forrest" Lecture, delivered before the Institution of Civil Engineers on June 18, by Dr. Franicis Elgar, F.R.S. 
designs and tenders, which is often very short. This is of the nature of engineering work of all kinds.

The nature of some of the principal problems that arise in the design of ships, and the extent to which their solutions are scientific, empirical, or merely tentative, will be indicated in some degrce as $I$ go on. I pass over what I venture to call the secondary problems of mensuration and hydrostatics - which relate to bodies floating in equilibrium in still water, and constitute the bulk of the ship-designer's purely scientific stock-in-trade-and will endeavour to direct attention to some of the fundamental problems of a ship's behaviour at sea. I do not underrate, however, the great importance of those passed over, for it is the results of mathematical and physical research into the still-water properties and conditions of floating bodies which enable us, with the aid of observation and experience, to judge the probable qualities and behaviour of ships at sea. They also furnish the best data for comparisons between ships of varying dimensions and forms.

The class of problems that demand attention first are those which bear the most directly upon safety at sea. These are very general and comprehensive in character, and are impossible of anything like complete solution from the purely scientific side; but they are of vital importance, and solutions of them, which will be upon the right side. have to be found somehow for every ship that is built.

The first in natural order of the problems that relate to safety is the maximum depth of safe loading, or the minimum sea-going freeboard for a ship of any given size or type.

The losses of cargo-steamers, and of lives at sea, became so serious twenty-five to thirty years ago that many attempts were made to get a law passed for limiting depth of loading. The great difficulty and complexity of the problem resisted for a long while all efforts to deal satisfactorily with it. It was considered by many authorities, upon all sides, to be impossible of solution: and yet individual shipowners, or shipping companies, were obliged to regulate the loading of their own ships in some way, and upon some system, or make it the duty of others to do so. It followed, therefore, that if the knowledge and experience of those separately responsible for the loading of the various types of vessels could be brought together and analysed, it ought to be possible to frame rules and tables of freeboard which would embody the results of safe loading, and prevent steamers being sent to sea in a dangerously overladen condition.

The present Board of Trade freeboard rules and tables, which limit, by an Act of Parliament passed in 1800, the depth of loading of British ships, were arrived at in this manner. The first official tables were prepared in 1885 by a committee appointed by $\mathrm{Mr}$. Chamberlain when he was President of the Board of Trade.

The close attention paid during recent years to the protection of openings in the weather-deck, in association with the strict limitation of loading now enforced by the Board of 'Trade freeboard tables, has resulted in an extraordinary diminution of losses at sea. The effect upon safety of the present regulations, and of the improvement all round in the size, strength, and equipment of ships is shown by the yearly statistics of losses, and it is well that the figures relating to these should be known. In the three calendar years $188 z_{-3}$ there were 1982 of the British ships registered in the United Kingdom, exclusive of fishingvessels, lost at sea from all causes-foundering, stranding, collision, and missing-and 5599 lives of crew in them, besides 332 passengers. For the three years ending June 30 , 1906, the corresponding figures were 654 ships, 1394 lives of crew, and 133 passengers-and more than 100 of these passengers were lost in the channel steamer Hilda, on her passage to St. Malo in November, rgos. number of lives of crew lost at sea has thus been reduced to one-fourth of what it was twenty-five years ago, while not more than thirty passengers, besides the unfortunate victims of the Hilda disaster, lost their lives in all the vessels, large and small, that were lost at sea during the three years ending June 30,1906 .

An important element of safety at sea is the division of the hull into separate water-tight compartments. A

No. 1969, vOL. 76] collision with another ship may occur, and it is necessary to provide, in such case, against being sent quickly to the bottom. Much attention has been given to this point during recent years, especially in large passenger liners. The number and positions of the water-tight bulkheads in these are often resulated so as to carry out the recommendations of the Board of Trade Bulkheads Committee, presided over by the late Sir E. J. Harland in I $89 \mathrm{I}$.

Compliance with the Bulkhead Committee's rules is optional on the part of shipowners, but, although they may be sometimes used as a guide in fixing the position of bulkheads, full compliance with their requirements is by no means general, even in the highest class of steamers.

The next point of vital importance to safety at sea is stability. The stability of a ship when floating in equilibrium in still water is readily calculated, and is represented graphically by curves which show at any angle of inclination what the righting moment is which operates to move her back towards the upright position supposing her to have been forcibly inclined away from it. It is thus determined very completely for the assumed still-water conditions, but the designer, although he is obliged to trust to his judgment for making it satisfactory for sea-going purposes, often knows little of what it may become under working conditions upon a voyage. I made two voyages in a large ccean liner not long ago, the metacentric height of which is about 7 inches when light and 18 inches when filled up with passengers, stores, fresh water, coals, and a homogeneous cargo of such density as conpletely fills all the cargo spaces and immerses her to her load draught. The metacentric height was 2 feet 2 inches at sailing upon the first voyage; at the middle of the voyage it was 21 inches, and at the end 20 inches. Upon the second voyage the metacentric heights were 2 feet 10 inches at starting, 16 inches in the middle of the voyage, and 20 inches at the end. The irregularities in the metacentric height from day to day were largely due to the manner in which the water-ballast was used. This was the case of an ocean liner, in which the weights carried were about one-half the fixed weight of the hull and machinery. In a large cargo-steamer, where the weights carried may amount to twice the weight of the hull and machinery, it will be seen how much the stability on service depends upon those who regulate the loading, and how little upon the designer.

The ship-designer requires to decide, of course, what metacentric height to give a ship in the circumstances to which his calculations apply, but it is only by comparison with other ships of similar types that have been found satisfactory after passing into the hands of their owners that he can properly fix the exact figure.

The question of stability was raised before the Loadline Committee of 1885 in connection with the regulation of freeboards, and has often been revived since. It has been felt however; that stability is so intimately related to stowage, and so much in the hands of those who regulate it, that it would be inpossible to treat stability satisfactorily as a mere factor of depth of loading. Nothing can make a ship safe if her stability is not secured by proper stowage; but when vessels will obviously admit of being loaded with homogeneous cargoes, so as to have their stability dangerously reduced at sea, the official bodies who assign load-lines should look for proof that the danger is understood, and that proper measures will be taken in regulating the stowage to guard against it. I understand this is the course taken by the Board of Trade and the authorities who assign freeboards when cases of such a nature come before them.

One of the most important elements of safety at sea is structural strength, and there is no more intricate or difficult problem which we have to consider. Mercantile steamers have been made what they are, in respect of design and strength of structure, chiefly by observation and experience of the effects of straining action at sea. The usual calculations of strength of structures do not carry us very far by themselves in shipbuilding, and although much attention has been given to these by ship-designers they cannot be greatly relied upon in practice. As a matter of fact, the arrangement of material shown upon the transverse section of a ship, and the sizes of the various parts, are practically what they have been made 
from time to time by Lloyd's Register Society. Classification at Lloyd's is so important in the mercantile marine for purposes of insurance that the design of a ship's structure is usually little, if any, more than compliance with Lloyd's rules and tables. These rules have been modified as ships have increased in size and varied in type; and when exceptional ships not directly provided for by the rules have to be classed, the structural design is specially dealt with by Lloyd's; but the governing principle throughout is experience of the behaviour of ships at sea.

Lloyd's Register Society has also done, and is still doing, much in the way of scientific research. It has a highly trained technical staff which has conducted and published some of the most valuable investigations yet made of the structural strength of ships; but the general problem of how to obtain the requisite strength of ştructure with the minimum weight of material is extremely difficult of approach from the scientific side. The usual calculations of structural strength are based upon stillwater conditions. The most important are those which relate to longitudinal strength, because the greatest stresses that can come upon a ship are in the longitudinal direction. In these calculations the structural portion of the hull is regarded as a steel girder supported over the whole of its length by the upward pressure of the water.

In order to approximate somewhat to the worst conditions It sea, the maximum stresses at the top and bottom are calculated for two hypothetical cases of support upon a wave surface. The surface usually taken is that of a trochoidal wave of the same length as the ship, the height of which is one-twentieth of its length. The vessel is first considered in equilibrium upon a wave-crest with her bow and stern in the adjacent hollows, and next to be supported at the ends upon two wave-crests with her midship part in the hollow between them. The whole system of wave-water is supposed, for the purposes of the calculations, to be fixed for the moment, and the ship to be floating upon it in statical equilibrium.

It is not known how nearly the results given by calculations, which rest upon assumptions that differ so widely from the real circumstances, correspond with the maximum stresses really brought to bear at sea, but it is certain that they are often much in excess of the truth. In the new big Cunarders, Lusitania and Mauretania, the limiting stress accepted by Lloyd's as determined by calculation was 10 tons per square inch for mild steel the ultimate tensile strength of which is 28 to 32 tons per square inch. This gives an apparent factor of safety of only 3 .

Many vessels have been running for vears in which the figures, obtained by similar calculations, for the maximum stresses would amount to 10 tons per square inch. This must be largely in excess of the truth, and it is impossible to say exactly by how much.

The quantitative values of the calculated stresses are thus Them doubtiul. Even in comparing them with figures obtained in a similar way for other ships, it is necessary to be careful not to press the comparison too far. Attempts have been madc to measure the actual stresses at sea upon portions of a ship's structure by means of strain indicators. Extensive experiments were carried out in H.M.S. Wolf a few years ago by an Admiralty Committee with Stromeyer's indicators, which gave some interesting results; but very little real progress has yet been made towards a quantitative solution of the strength problem.

The Great Eastern proved, by her Atlantic voyages to New York and Quebec, and her subsequent experiences in the trying work of cable-laying in the Atlantic, that she was quite strong enough for anything required of such a ship; and if we compare her structure with that of the standard ship of her dimensions and type to-day, which embodies the results of fifty years' more experience than her hesigner had at command, it appears very remarkable. Sir $\mathrm{W}$. White came to the conclusion, which I believe is right, that after making full allowance for features of modern designs, that involve additional weight, which the Great Eastern did not possess, her structure was lighter than that of the corresponding ship of to-day, although the ship of to-day is built of steel 5o per cent. stronger than the iron plates of the Great Eastern, and the riveting of the edges and butts of plating is much more extensive and No. 1969, VOL. 76$]$ efficient, and is performed by hydraulic power in those parts where strength is most important.

The difference in principle between the two designs is so great, and the comparison of the weights of material they require is so much in favour of the Great Eastern, that there certainly seems to be a case for careful investigation, and for seriously considering whether a radical change in the structural design of large ocean liners might not be made with advantage. Novel structural arrangements are constantly being introduced into the design of cargo-steamers in order to give large open holds and to facilitate stowage. Some of these are now being built of large size and depth, with only a single strongly plated deck at the top, and there seems no reason why this principle should not be applied to large passenger vessels. Any saving of weight thus effected would not only be a saving of cost, but would better enable the difficulties of draught of water in harbour and docks for the largest ships to be overcome.

The problem of speed has always been a very vexed and difficult one, and there is none which has caused more trouble, or given rise to more fallacies in theory and errors in solution. I cannot even direct attention to the numerous theories and the various approximate formulas that have been invented and employed from time to time for explaining and solving the speed problem. These formulas are generally so restricted in their range of application, and require so much knowledge of their limitations and the conditions under which they can alone be relied upon for results that will be approximately near the truth, as to prove dangerous traps to the unwary and ill-informed. The man who can use these intelligently and safely, and with full knowledge of their limitations and their tendencies to error, is able to deal with the speed problem much more completely and effectively - and I shall confine my remarks to the way of doing that.

The practical solution of the speed problem was effected by the late Mr. William Froude when he discovered the law of similitude or comparison which enables the resistance of a model, as ascertained by experiment, to be used for calculating the resistance of another model upon a different scale, or that of a full-sized ship of similar form. His analysis of the separate elements of resistance, showing that the two great ones, friction and wave-making, varied independently of each other, and the latter in a very irregular manner, explained why simple approximate formulas are so untrustworthy.

What is wanted for the practical purposes of a designer is the means of ascertaining the resistance of a ship of given dimensions at any desired speed; and also of readily determining the precise form or degree of fineness of under-water body that would enable the maximum of carrying power to be obtained at a moderate rate of fuel consumption. It is one thing to know exactly what power is required to give a ship of given dimensions and form the speed asked for or promised, and quite another to determine what are the dimensions, form, and degree of fulness that will give the maximum passenger and freight carrying capacity with moderate engine power and expenditure of fuel.

In order to exhaust the problem of the best form of ship to meet the requirements of any particular trade or service, considerable investigation is required. This can only be made satisfactorily by testing the resistances of models in an experimental tank upon the late Mr. Froude's system.

That method is unfortunately impracticable, however, for ship-designers in this country, because there is no experimental tank here available for general use. The very few that exist belong either to the Admiralty or to private shipbuilders, and are confined exclusively to the work of their respective owners. I have had experiments made occasionally for my own purposes, but had to go abroad for them. The experiments required by Mr. Yarrow for his valuable investigations into the effect of shallow water upon speed were made in the North German Lloyd tank at Bremerhaven, where other experiments have also been made for him. A British shipbuilder can only get such experiments made by setting up an independent establishment for himself or going abroad. Now an experimental tank, with its equipment and a competent staff for work- 
ing it, is very costly to create and to maintain; and over and above the cost of construction, and of running it, there is the all-important question of the quality of the results it will produce. It is not enough to procure a tank with all its apparatus and appliances and to attach to it a staff of scientific men to run models and take records of their speed and resistance. The work is of so delicate and intricate a nature that the personal qualities of the experimenters count for very much in it. The results obtained by the late $\mathrm{Mr}$. W. Froude and the present $\mathrm{Mr}$. R. E. Froude owe much of their value to the exceptional qualifications of those eminent men for scientific research, especially upon the experimental side. It is the men, and not the tools, who constitute the most important factor in work such as this, and the right men for it are very difficult to obtain and to keep.

An attempt has recently been made to provide an experimental tank at the National Physical Laboratory, to be worked by members of the staff there, at which ship models might be tested for resistance, but up to now this has been without result. There is another way of dealing with the matter, however, and a readier one for the ordinary purposes of the ship-designer, which has been initiated by Mr. R. E. Froude, that promises to overcome the difficulty in a satisfactory manner. Mr. Froude read a paper at the Institution of Naval Architects, three years ago, upon "Some Results of Model Experiments," in which he gave results of a series of general experiments on systematic variations in form of hull, the variations consisting of six different sets of typical lines, varied in proportion by independent variations of length, beam, and draught. The resistance data given by these experiments are published in the paper in such a form that the resistance of a ship of any dimensions, the lines of which are similar to the typical ones, which are also given, can be readily taken out. The types dealt with have block coefficients, or ratios of displaced volume to product of length, breadth, and draught, varying from 0.4865 in the finest to 0.541 in the fullest. Now this covers a very important class of mercantile steamers-that of fast Channel boats-and the designer of such a boat could have nothing better for his speed calculations than the data in this paper. $\mathrm{He}$ has only to refer to Mr. Froude's tables and diagrams in order to determine at once the proportions and form that will best suit the circumstances, and to construct the lines of his boat.

If similar data could be obtained for other forms of ships, say for the fast-liner type, with block coefficients varying from about 0.6 to 0.7 , the designer of that class of vessels would indeed have cause to be grateful. The best practical solution of this long-vexed problem of the relation of power to speed appears to be an extension of Mr. Froude's system to vessels of the fast-liner type, and to others with which the ship-designer ordinarily has to deal, leaving those of abnormal proportions or form, and also the work of general research, to a public experimental tank-if ever we find enterprise enough among those interested to get one set up in this country.

The resistance of a ship may be estimated to a close degree of accuracy in the manner mentioned, but the determination of the engine power required to overcome that resistance involves the important consideration of screw-propeller efficiency. The problem of the most efficient design of propeller for any given size and form of ship and rate of turning of shaft is as yet far from practical solution. Model experiments have been carried out at Haslar with a large number of propellers of varying pitch, diameter, and developed area, but these model screws have been very small, as the size and speed at which they could be worked were limited by the stresses the experimental mechanism is capable of bearing.

Further advance might be effected by carrying out experiments on a larger scale than those already made, and with stronger appliances than those now used for the purpose in the Admiralty tank. A still more effective means, which I hear is under consideration by $\mathrm{Mr}$. Froude, would be to build an experimental launch for the purpose, to be run in open water and propelled by machinery of considerable power. The propelling machinery could be so arranged that the thrust of the screws and the torque on the shaft would be automatically recorded, as in the case of tank experiments. With such an arrangement screws up to 3 feet in diameter could be experimented with-a great advance on anything that could be hoped for in the tank-and the important problem of propeller efficiency might thus be brought much nearer to a practscal solution.

We now come to the greatest problem of all with regard to the propulsion of ships, and that is the form which propelling machinery is likely to take in the immediate future. Already an important change is in progress from the ordinary reciprocating marine engine to the steam turbine, and the question is not only how far that change will extend, but whether the whole of the cumbrous apparatus required for. producing steam may not before very long be swept out of mercantile steamers, and the power be obtained from some form of internal-combustion engine. Very few ocean steamers have been fitted with turbine machinery or are being so fitted, and although this may not cause surprise in the case of cargo-boats and other vessels of low or even moderate speeds, it may appear strange that liners of high speeds are still being fitted with reciprocating engines, and that the bold lead given by the Cunard Company with their two fastest new boats and the Carmania should not be generally followed.

The chief reason for hesitation to put turbine machinery into ocean liners is the doubt which exists as to coal consumption. The amounts at stake are so large in these costly vessels when experiments with novel propelling machinery are tried that everybody prefers to see someone else make them. The Cunard Company is making the crucial experiment upon the largest scale that is now possible, and everyone interested in progress must wish those responsible for it all the success they hope for and deserve; but the result is to some extent uncertain, and the immediate future of the turbine in fast liners depends greatly upon it.

In warships the consumption of coal has been brought down to about $\mathrm{I} .7 \mathrm{lb}$. per equivalent I.H.P. of reciprocating engines per hour, and the same in mercantile boats of cross-Channel type. That is as good as can be obtained with reciprocating engines in the same classes of vessels, as weight has to be kept down as much as possible in these by shortening the stroke, and using high mean pressures of steam in the cylinders, in order to get all the power that is practicable out of a moderate size and weight of machinery. It pays better, in these cases, to stop somewhat short of the maximum efficiency that is attainable than to carry the additional weight which the increase would involve. In ocean liners the conditions are different, and economy of consumption is there the chief point aimed at. Their consumption with quadrupleexpansion engines and a boiler pressure of $2 \mathrm{ro} \mathrm{lb}$. to $220 \mathrm{lb}$. per square inch has been brought down to $\mathrm{I} \cdot 3 \mathrm{lb}$. of coal per I.H.P. per hour for all purposes. The substitution of turbines for reciprocating engines in ocean vessels depends chiefly upon whether the consumption with turbines can also be brought down to this low figure, and there is no satisfactory evidence that this is now practicable. It appears probable that the marine turbine may ultimately be so improved as to beat the best reciprocating engines in economy of consumption in ocean liners, but no proof is forthcoming that it can yet be relied upon to do it.

The correct measurement of the power given out by turbine machinery is a practical problem of great importance. Considerable success has been achieved with a telephonic recording apparatus for indicating the twist of a shaft over a given length, and thus giving a measure of the torque. The record is not always, however, so definite and accurate as could be desired. A satisfactory solution of this problem is much required by ship designers.

The question of some form of internal-combustion marine engine suitable for large ocean vessels is still about where it was when Mr. Milton's paper was read and discussed here last January, and I do not feel able to add anvthing with advantage now to that paper and discussion. I will therefore merely enumerate the conditions, most of which were mentioned by Mr. Milton, that must be satisfied by a successful marine engine of anv type whatever:-

(I) The engine must be reversible.

(2) It must be capable of being stopped quickly, and of being started quickly either ahead or astern. 
(3) It must be capable of being promptly speeded to any desired number of revolutions between dead slow and full speed, and of being kept steadily at the required speed for any length of time. "Dead slow" ought not to be faster than one-quarter of full speed, and should be less in very fast vessels.

(4) It must be capable of running continuously for long distances, with but short intervals between the runs, without risk of stoppage or breakdown.

(5) It must be capable of working well, not only in smooth water, but also in heavy weather in a seaway, where the varying immersion of the propeller causes rapidly changing conditions of resistance.

(6) All working parts must be readily accessible for overhauling, and all wearing surfaces must be capable of being promptly and easily adjusted.

(7) The engine must be economical in fuel, especially at its ordinary working speed.

(8) It must be compact, light in weight, and well balanced so as not to cause vibration.

(9) It must not involve any risk of accumulation of gas in the ship such as could form an explosive mixture.

(ro) It is a sine qua non that it must be capable of using a fuel the supply of which at moderate price is practically unlimited, and that could be obtained readily in whatever part of the world a ship might happen to be.

Engineers and metallurgists may together succeed in overcoming some day the difficulties of producing large cylinders which will stand the high impulses and great and rapid variations of temperature that occur with internal combustion, but until that is accomplished no great step ahead can be taken. There are no two opinions, however, as to the advantages that would be gained by doing away with the present boilers and their appurtenances, and abolishing with them much of that very arduous and disagreeable class of labour known as marine stoking.

The subject of oil fuel for marine boilers is interesting, but I have no time to say more than that great practical advance has been made with it during the last decade, and a consumption as low as $0.91 \mathrm{~b}$. per I.H.P. per hour has been regularly realised in mercantile vessels which employ the system of spraying the liquid for combustion by means of hot air. American steamships have used oil fuel largely during the last three years, under a combined system of high and low pressure air respectively for desiccating or pulverising the oil before combustion and for assisting the combustion afterwards. This system has proved highly successful and economical. Vessels of 14,000 tons displacement belonging to the Shell Transport Company have made voyages regularly and successfully from Singapore to this country by the long route of the Cape of Good Hope, and still larger vessels have made equally successful voyages from New York to San Francisco.vià Cape Horn.

The securing of all the comfort that is possible for passengers on board ship is a modern idea. Formerly it was thought sufficient to take them safely, and without much regard even to time, to their destination, and very little attention was paid to comfort. Now it is the chief object of the best shipping companies to leave and arrive in port on fixed days, and even at fixed hours, and to make the life of passengers on board ship as comfortable and luxurious as on shore.

Much of the comfort and luxury now in such demand by passengers is provided by those who manage the ships, and not by their designer. There is one very important element of comfort, however, which the designer can do much to supply, and to which increasing attention is given. I refer to steadiness at sea, and freedom from heavy rolling and pitching. But whatever may be done by the designer to give a metacentric height favourable to steadiness, its proper regulation at sea by suitable stowage of cargo and stores in the first instance, and by the judicious use of water ballast afterwards, requires the careful and close attention of the ship's officers if unpleasant rolling is to be kept at a minimum. About 18 inches of metacentric height appears to give a satisNO. I 969, VOL. 76] factory combination of resistance to inclination in large ships with a long rolling period.

After reducing the tendency to roll as much as possible by suitable regulation of the metacentric height, the next thing is to increase the resistance to whatever rolling there may be. This is done chiefly by means of bilge keels, which oppose the whole of their surface to the motion of rolling, and are very effective in reducing its extent when they are of sufficient depth. In ships I have known that have been fitted after they were built with bilge keels suitably formed and placed, the extreme angles of rolling have been reduced to one-half. Their steadying effect is now well known and admitted in the mercantile marine.

Other devices have been considered, and some have been tried for still further increasing the resistance to rolling. Sir Philip Watts described in the Transactions of the Institution of Naval Architects for 1883 and 1885 the trials in H.M. ships Inflexible and Edinburgh of free water in large chambers that extended right across the lower deck, the transverse motion of which, as the ship rolled, was regulated by the shape of the waterchamber and the depth of the water, so that it would operate as a drag or brake upon the rolling motion. The same device was tried in a small passenger ship, the Ohio, in 1887, and in the City of New York and City of Paris in 1889. In the two last-named ships the chamber was upon the orlop deck. These water-chambers appear to have given good results within certain limits of rolling and when the motion of the water in them was well timed, but the action upon the rolling depended very much upon the way in which the water was regulated. Whether it was on account of this or because of the space occupied, or other objections that exist to the free motion from side to side of large quantities of water in a ship, I do not exactly know, but whatever the reason may be the idea has been dropped.

A proposal has recently been made by $M$. Victor Cremieu, of Paris, to check rolling by means of a heavy pendulum of long period that would oscillate in a closed chamber filled with viscons fluid, and he has contributed a paper upon the subject to the Académie des Sciences. $\mathrm{His}$ idea is to make the length of pendulum and its weight such as would give it an angular moment up to possibly one-tenth that of the ship. The clearances between the pendulum and the sides of the chamber, and the degree of viscosity of the liquid-M. Cremieu suggests oil, or a mixture of water and glycerin-would be so arranged as to make the energy of the pendulum most effective in offering resistance to rolling. A simplification of the apparatus is suggested by substituting for the pendulum a weight that would move backwards and forwards upon a curved path in a transverse chamber or tube filled with the viscous liquid. In both cases the principle is that of opposing the rolling of the ship by the statical moment of the oscillating weight, and reducing the energy of motion by generating heat in the fluid through which the weight moves.

Sir John Thornycroft described an automatic steadying anparatus in 1892 , which was fitted in his steam-yacht Cecile with some success. It consisted of a most ingenious controlling gear which regulated the motion from side to side of a heavy weight in opposition to the rolling motion. It was very cleverly worked out, and destroyed much of the rolling in a vessel of great metacentric height and very short period. This idea also has not been followed up.

A device which appears promising for increasing the resistance to rolling is one that has been ingeniously and effectively worked out by Dr. Otto Schlick, of Hamburg, a very eminent marine engineer. It depends upon gyroscopic action, and its principle was fully described by $D_{\text {r. }}$. Schlick at the Institution of Naval Architects in IoO4 This principle appears to deserve serious consideration, and is already ripe for application to the smaller classes of steamers. I am informed that an apparatus is being manufactured for placing in the Hamburg-American Company's passenger-boat Silvana, of about Iooo tons, which runs between the Elbe and Heligoland, and that Dr. Schlick is designing a standard gyroscope that will be suitable for 
boats of about 1200 tons to 2000 tons displacement. This standard gyroscope will be electrically driven, except in cases where there is not a sufficient margin of electric power available in a ship, when it would be driven by a steam turbine. An apparatus for vessels of the displacement named would be applicable to the class of Channel steamers, and we may perhaps see it tried before long in some of them.

What I have said with regard to making ships steady at sea has had reference only to rolling inotion; but many persons consider it is not rolling that affects them so much as pitching, or as the skew motion near the ends of a ship that is neither rolling nor pitching, but an unpleasant combination of the two. There is also sometimes a vertical or heaving oscillation when large waves are passing a ship broadside on which may rise to an amplitude of several feet when the wave-period approximates to the period of her own dipping oscillations, but it is probably seldom that the motion from this cause is great. Pitching is often the chief cause of trouble and discomfort, and the motion due to it may be greater and more violent than any other, especially near the ends of the ship. The pitching period is sometimes as short as four seconds, so that there may be three or four pitches to one roll; and the vertical distance moved through near the ends in pitching is very much greater than at the ship's side during a roll.

After all has been done in the way of making the forward transverse sections of a ship such as will best resist plunging into the sea, and by good stowage, there still remains considerable tendency to pitch in certain conditions of sea which cannot be removed. The best way to avoid the ill effects of pitching is to get as near as possible to the axis of rotation, the position of which varies considerably according to the nature and direction of the seas which cause the pitching, but is, on the average, not far from the centre of length. The modern large steamers which have their first-class passenger accommodation upon three or four decks in the middle third of a ship's length are generally found to be the most easy and comfortable at sea. That is no doubt largely because the greatest vertical distance moved through in pitching in the passenger accommodation is only one-third of what it is at the ends of the ship. It is to this concentration of passenger accommodation near the middle of a ship's ength that we have to look chiefly for neutralising the trying effects of pitching.

One of the chief causes of discomfort and distress to passengers on shipboard is vibration. This may be due to one or more of several causes, to which much attention has been given during recent years. The effect of reciprocating engines in causing vibration has been investigated by Dr. Schlick, Mr. Yarrow, Mr. Mallock, Prof. Dalby, and others, who have demonstrated the manner in which such engines operate to cause vibration, and how to reduce this effect to a minimum by suitable design, and by balancing the principal working parts. 'There is little to choose, in a strongly built ship, between modern wellbalanced reciprocating engines and steam turbines as regards smoothness of running and absence of unpleasant vibration. Vibration is often due to the action of the propellers, and when these have to run at very high speeds, as with fast-running turbines, a certain amount of vibration is sometimes unavoidable. Apart from the essential conditions of trueness of propeller blades and exact balance of the propellers upon their shafts when turning, there is the action of the ends of the blades upon the water adjacent to the stern-plating where they pass nearest to it in revolving, which causes a hammering effect that is sometimes very great. The vibration and tremor of this plating may be quite local, and may be readily checked by strong bracket frames at the part where it is greatest; or it may be communicated throughout the hull, and set up sympathetic vibrations in large flat areas of plating, such as decks, straight side-plating, bridges, \&c. These difficulties can generally be overcome by careful attention to the surfaces that vibrate, and by stiffening or supporting them at a few critical points by struts or brackets. There appears no reason why ships should not now be kept free from all unpleasant vibration, whether as regards the working of the main engines or the action of the propellers.

The tendency to increase the size of ships is strong and continuous. It has long been known, and experience proves that the power required to drive a ton of a ship's displacement at a given speed diminishes, and the working expenses become less per ton all round, with increase of size.

There is a size and speed of ship that is most appropriate and profitable for each line of steamers, or each trade, and it varies greatly in different trades. It is the managers of the various lines who know best what dimensions and speed are likely to be most profitable in their respective trades, and what are the maximum number of passengers and quantities and descriptions of cargo likely to be forthcoming. The approximate size, and the speed, of mercantile steamers depend upon commercial and economic considerations which the ship-designer usually has but an imperfect knowledge of. His part consists in producing a design that will fulfil the necessary conditions of size, draught of water, speed, carrying capacity, and accommodation for passengers in the most efficient manner and at the minimum of cost. There is one point, however, which is so important in considering further large increases of speed in ocean liners generally that I would like to direct attention to it.

Speed is limited in passenger liners, altogether independently of size, by economic considerations. High speed at sea is a costly luxury. It can be obtained by paying for it-up to $25 \mathrm{knots}$, as we see by the latest Cunard liners--but it has to be paid for by somebody. The extra cost cannot be got out of cargo freight, for as speed is increased the proportion of space available for carrying cargo becomes reduced by the increase of boilers and machinery, and therefore less cargo is carried relatively to the size of the ship. This reaches an extreme limit in the fastest Atlantic liners, the holds of which are as full as they can be stowed of engines, boilers, and coals for the voyage-their speeds only being limited by the impossibility of getting more boilers in-and it is only a ferv odd spaces which cannot be utilised for other purposes that are available for carrying a little cargo. In these cases cargo is reduced almost to a negligible quantity.

It may be said generally, as regards any line of steamers, that if speeds of more than 12 to 13 knots are desired the extra expenditure involved by such increase must be looked for outside the cargo. This element of earning power does not bear an increase of rate of freight. There are only two sources from which payment of the extra cost of increased speed can come. One is from passengers and the other from a mail subsidy. No mail subsidy that could be proposed would pay more than a small proportion of this extra cost ; the greater part of it must come from passengers. What passengers have to pay for high speeds at sea may be seen by the rates charged in the fastest Atlantic steamers. Apart altogether from special cabins, or apartments de luxe, for which almost any prices are paid, the cost of a single first-class passage to New York varies from 22l. Ios. to $48 l$. 10s. for a run of six days, in one of the fastest liners, according to the position of the cabin in the ship and the time of year, or from $1 \frac{3}{4} d$. to nearly $4 d$. per mile travelled. The prices have risen rapidly during recent years as speed has been increased, and passengers across the Atlantic appear to be forthcoming in ever-increasing numbers who are ready to pay them. If that were not the case such high speeds could never have been reached. No great improvement of speed is to be looked for upon the other main lines of ocean traffic, unless some revolutionary change is made in the mode of propulsion which will cut down the cost, or a sufficient number of passengers are found, as in the Atlantic trade, who will pay the higher rates it necessitates.

I have not done anything this evening towards reducing the number of the many and difficult unsolved problems that trouble the mind and tax the skill and iudgment of the ship-designer, but if I have succeeded in conveying some idea to you of their nature, and of the interdependence of science and engineering in all wise attempts at their solution, I shall have accomplished my obiect. 